Kansas State University Libraries

New Prairie Press

\title{
DEVELOPING ACCURATE SPATIAL MAPS OF COTTON FIBER QUALITY PARAMETERS
}

Gretchen F. Sassenrath

Follow this and additional works at: https://newprairiepress.org/agstatconference

Part of the Agriculture Commons, and the Applied Statistics Commons

\section{(c) $(1) \ominus$}

This work is licensed under a Creative Commons Attribution-Noncommercial-No Derivative Works 4.0 License.

\section{Recommended Citation}

Sassenrath, Gretchen F. (2008). "DEVELOPING ACCURATE SPATIAL MAPS OF COTTON FIBER QUALITY

PARAMETERS," Conference on Applied Statistics in Agriculture. https://doi.org/10.4148/2475-7772.1103

This is brought to you for free and open access by the Conferences at New Prairie Press. It has been accepted for inclusion in Conference on Applied Statistics in Agriculture by an authorized administrator of New Prairie Press. For more information, please contact cads@k-state.edu. 


\title{
DEVELOPING ACCURATE SPATIAL MAPS OF COTTON FIBER QUALITY PARAMETERS
}

\author{
Gretchen F. Sassenrath \\ USDA-ARS Application and Production Technology Research Unit \\ Stoneville, MS 38776
}

\begin{abstract}
Awareness of the importance of cotton fiber quality (Gossypium, L. sps.) has increased as advances in spinning technology require better quality cotton fiber. Recent advances in geospatial information sciences allow an improved ability to study the extent and causes of spatial variability in fiber parameters. However, these studies are often harvested by hand and ginned on small research gins. Fiber quality from cotton lint harvested and ginned in this manner is different from that machine-harvested and ginned on production-scale equipment. The objective of this study was to develop a method of correcting for error introduced into cotton fiber quality parameters from samples as a result of harvest and ginning methods. This correction method will allow more realistic comparisons between results that researchers commonly report and measurements that a producer would receive. Field-grown cotton was harvested either by machine or hand, and ginned on a small research gin or a production-scale gin. The results reported here examine the population characteristics for physiological fiber parameters including micronaire, strength, length and uniformity. The correction needed for translating the research results to the production scale was determined. The error inherent in that correction was determined for different populations of cotton fibers from different years. To demonstrate the impact of the research-induced error and the correction factor, spatial maps of cotton fiber length are plotted.
\end{abstract}

Keywords: cotton fiber quality; cotton fiber variability; spatial variability

\section{INTRODUCTION}

The introduction of the cotton (Gossypium hirsutum, L. sps.) yield monitor has allowed growers to identify regions within production fields that vary in lint yield (Wilkerson et al., 2001), and take corrective measures to better match inputs to potential profits. Cotton fiber quality directly impacts the value of the cotton, and hence the potential profitability (Sassenrath et al., 2004). Knowledge of the spatial variability of the crop value is needed to develop site-specific management scenarios that optimize profitability. In cotton, this requires information of both the spatially registered yield and the cotton quality. Moreover, to better explore the impact of soil and biotic factors on cotton fiber development, we need information on the spatial variability of cotton fiber parameters. Information on the spatial variability of fiber quality comparable to that for cotton yield, however, is not readily available.

Previous research studies demonstrating the extent of spatial variability of fiber properties have relied on hand-harvesting the cotton at intervals throughout the field (Elms and Green, 1997, 
1998; Elms et al., 2001; Johnson et al., 2002; Ping et al., 2004; Davidonis et al., 2004). However, hand-sampling is not amenable to production-scale cotton harvesting because of the time and labor required, and because of biases in hand collection of cotton bolls (Calhoun et al., 1996). We have developed an automated sampler for a cotton picker that removes a portion of the seed cotton during the harvest operation (Sassenrath et al., 2005), making it more feasible for use in a production setting. While this system allows rapid, georeferenced collection of samples over a large area, it is still limited by the small size of the cotton samples, requiring ginning on a small-scale research gin. The differences in fiber properties resulting from the harvest and ginning methods used in cotton fiber spatial variability studies limit the extension of these research results to the production setting.

Harvest and ginning operations alter cotton fiber properties (Williford et al., 1987; Williford, 1992; Calhoun et al., 1996; Dunn et al., 2002; Braden et al., 2004). Guo et al. (2004) noted differences between cotton lint from small research gins and production gins, especially in micronaire values. While Gannaway et al. (2004) concluded that grab samples collected from the weigh wagon after mechanical harvest were comparable to producers' results, they did note that length, strength and uniformity were better in the grab samples. Calhoun et al. (1996) found that, although hand-sampled cotton showed a greater correlation with machine-harvested cotton, the hand-harvested cotton reflected a tendency to select better developed bolls than machine harvesting or grab samples. They found an increase in micronaire and fiber length with hand sampling.

This study was undertaken to quantitate differences in cotton fiber characteristics between researcher and producer-scale harvest and ginning methods and test the accuracy of methods of correcting for research-induced errors. This report examines changes in four major fiber properties that have been found to vary with harvest and ginning operations: micronaire, strength, length and uniformity. Once corrected, spatially accurate maps of cotton fiber properties are compared.

\section{MATERIALS AND METHODS}

\subsection{Cotton production}

Cotton (Gossypium hirsutum, L., sps.) was planted in 2003 and 2004 in research fields at the Delta Research and Extension Center in Stoneville, MS following standard agricultural practices. In 2003, Suregrow 215 BR/RR was planted, and two rows harvested for each sub-sample for a total of 120 subsamples. In 2004, DP 555 BR was planted in the field. Two rows were harvested for each sub-sample at each of the two harvest times, for a total of eighty samples per harvest time. All agricultural inputs were identical throughout the field, and were optimal for insect and weed control and irrigation.

In 2003, all cotton was harvested on one date. In 2004, two separate harvest dates were used to increase the range of variability of the cotton quality due to weathering. Each pair of rows was considered one sample. Cotton was first harvested by hand by picking one hundred bolls of cotton from each pair of rows. To minimize bias with hand-harvesting, the hand-harvesting was 
performed by marking off a starting point in each row, and harvesting all open bolls from that point on until 100 bolls had been harvested. Fifty bolls were harvested from each of the two rows of cotton, and combined for the 100 boll samples. The remaining cotton in each pair of rows was harvested with a two-row cotton picker (JD 699, John Deere, Co., Iowa) equipped with a sampling system that collected all the cotton from each row separately into two sacks. The sacks were weighed separately, and a grab sample removed for ginning on the small research gin. The sacks were then combined and ginned in the production scale gin.

\subsection{Cotton ginning and Classing}

Small ( $\sim 800 \mathrm{~g})$ samples of cotton from the hand harvest and machine harvested grab samples were ginned on a 10-saw research gin (Continental Eagle, Co., Memphis, TN). No seed-cotton or lint cleaning systems were used with the 10 -saw research gin. Large $(20 \mathrm{~kg})$ samples of cotton from the machine harvest were ginned at the microgin in the USDA-ARS Ginning Lab in Stoneville, MS, using one lint cleaner, two cylinder cleaners and one stick machine. This gin is similar to a full-scale production gin. Heating was used as needed to dry the cotton, depending on year. Sample labels are abbreviated as MH-PG (machine harvested, production gin), MH-RG (machine harvested, research gin), and HH-RG (hand harvested, research gin). All lint samples were classed at the USDA-AMS classing office in Dumas, AR, for determination of color, staple, micronaire, extraneous matter, strength, HVI color, color rd, color $+b$, classer leaf, HVI trash, length and uniformity.

\subsection{Data Analysis}

The large sample sets were randomly divided into "known" populations for development of correction factors and "unknown" populations for testing the accuracy of these correction factors. From the 120 sample set from 2003, 80 samples were randomly selected for the "known" group and 40 were assigned to the "unknown" group. Fifty four samples were randomly selected from each of the harvest times from 2004 for the "known" group, with the remaining 26 samples assigned to the "unknown" set. This allowed us to test the accuracy of the correction factor applied to a different population than that from which the original data was developed.

In addition, the "known" populations from 2003 and 2004 Early were combined for a "known" population (labeled $2003+2004$ Early) of 134 samples. The similarity in harvest times was the reason for combining these populations. The final correction was determined from a combined population of all "known" populations from 2003, 2004 Early and 2004 Late, for a "known" population of 188 samples representing all the sampling times. In this way, differences across years and harvest times could be reduced. This allowed determination of the accuracy of using the correction factors across years and with different sets of fibers.

Data analysis was performed with Excel (Microsoft) and SigmaStat and graphs were generated in SigmaPlot (SyStat Software, Inc., Point Richmond, CA). Data are graphed as box and whiskers plots to show the extent of population values for each parameter. The "box" contains data within 25 to 75 percentiles. The median and mean are lines within each box. The "whiskers" are error bars delineating $90^{\text {th }}$ and $10^{\text {th }}$ percentiles. Outlying points are presented as individual data points above and below the box. 
Control groups were used to develop correction factors for the fiber properties (Table 1). Each parameter from the MH-RG and HH-RG "known" samples were corrected to the mean of the MH-PG results from the same population. Correction factors were determined for 2003, 2004 Early, 2004 Late, 2003 + 2004 Early, and All (2003 + 2004 Early + 2004 Late) control samples combined. The correction factors were then applied to the "unknown" MH-RG and HH-RG samples from each of the sampling dates. The PROCMIXED procedure in SAS was used to determine Least Squared Means and Differences between LSM between the corrected populations and the MH-PG samples from the "unknown" sample set.

Georeferenced samples were mapped in ArcView (ESRI, Redlands, CA). Interpolation of data points was performed with Spatial Analyst, using a regularized spline, with 12 points and a 0.1 weight.

\begin{tabular}{cccrr} 
Machine harvested research gin & Micronaire, \\
units & $\begin{array}{r}\text { Strength, } \\
\text { g/tex }\end{array}$ & $\begin{array}{r}\text { Length, } \\
1 / 100 \text { in }\end{array}$ & $\begin{array}{r}\text { Uniformity, } \\
\text { Percent }\end{array}$ \\
\hline \hline 2003 & 0.4125 & 0.5463 & 2.4375 & 1.2125 \\
\hline 2004 Early & 1.7051 & -0.6132 & 2.4147 & 1.1034 \\
\hline 2004 Late & 1.5926 & -1.3741 & 2.0185 & 0.9259 \\
\hline 2003 and 2004E & 0.9455 & 0.0694 & 2.4047 & 1.1782 \\
\hline All & 1.1282 & -0.3459 & 2.2966 & 1.1025 \\
\hline
\end{tabular}

\begin{tabular}{ccccr}
$\begin{array}{c}\text { Hand harvested research gin } \\
\text { Micronaire, } \\
\text { units }\end{array}$ & $\begin{array}{r}\text { Strength, } \\
\text { g/tex }\end{array}$ & $\begin{array}{r}\text { Length, } \\
1 / 100 \text { in }\end{array}$ & $\begin{array}{r}\text { Uniformity, } \\
\text { Percent }\end{array}$ \\
\hline \hline 2003 & 0.5625 & 0.4813 & 2.3750 & 1.1875 \\
\hline 2004 Early & -0.8519 & -1.1037 & 0.3333 & 0.5741 \\
\hline 2004 Late & -0.6296 & -0.2167 & 1.2778 & 1.1667 \\
\hline 2003 and 2004E & -0.0075 & -0.1575 & 1.5522 & 0.9403 \\
\hline All & -0.1862 & -0.1745 & 1.4734 & 1.0053 \\
\hline
\end{tabular}

Table 1. Correction factors developed from "known" sample group from differences in mean between the MH-PG fiber properties, and $\mathrm{MH}-\mathrm{RG}$ and HH-RG samples. Fiber populations are from each year, 2003, 2004 Early, 2004 Late, and combined populations of $2003+2004$ Early and All (2003 + 2004 Early + 2004 Late) fiber samples.

\section{RESULTS AND DISCUSSION}

Parameters dependent on physiological processes during fiber formation include micronaire, strength, length and uniformity. Of the physiological parameters, micronaire showed the greatest variability within each population (Fig. 1 A, B, and C), especially for the 2003 samples. The production ginned samples had less variability in micronaire values, while research ginned samples had an expanded range of values, with a slight increase in overall population mean. 
However, statistically significant differences in micronaire values between populations were seen only in the $2004 \mathrm{MH}-\mathrm{RG}$ populations for both harvest times (Fig. $1 \mathrm{~B}$ and C). Strength was different between the $\mathrm{MH}-\mathrm{PG}$ control and both $\mathrm{MH}$ and $\mathrm{HH}$ samples for all harvest times except the late 2004 hand-harvest population (Fig. 1 D, E and F), though the direction of the difference was not consistent. MH-RG samples had reduced strength from both harvest times in 2004, while strength increased in the MH-RG population over the MH-PG control from 2003. Changes in length with ginning and harvest were more consistent across populations. Length increased in all samples ginned on the research gin, except those hand-harvested from the early harvest date in 2004 (Fig. 1 G, H and I). This is consistent with the damage to cotton fibers from the lint cleaners used in the production-scale gins. Reduced length of the HH-RG 2004 Early samples could result from inclusion of immature bolls during harvest. These bolls would have been eliminated from picking by the mechanical harvester, and hence not contribute to total fiber properties. Uniformity was consistently increased in samples that were ginned on the research gin (Fig. $1 \mathrm{~J}, \mathrm{~K}$ and $\mathrm{L}$ ), with an increase in the within population variability, particularly for the hand-harvested samples.

Research samples (MH-RG and HH-RG) from the "unknown" set were corrected using the factors developed from comparing research samples (MH-RG and HH-RG) from the "known" set to the production samples (MH-PG). Correction factors are reported in Table 1 for individual harvest times and combined populations. Uncorrected and corrected populations were tested with PROCMIXED in SAS to determine extent of variation. The Differences in Least Square Means, along with T-value and probabilities are reported in Tables 2 and 3 for each of the fiber parameters from the populations. In order for a correction factor to be useable, it must be appropriate for different environments (years) and different cultivars. Some of the fiber parameters were best corrected by correction factors from combined populations, such as micronaire from HH-RG samples $(2003+2004 \mathrm{E}$ correction factor). Surprisingly, the 2003 correction factor was most frequently the best correction factor, regardless of year. Length and Uniformity from HH-RG, and strength from both $\mathrm{MH}$ and $\mathrm{HH}-\mathrm{RG}$ samples showed optimal correction using the 2003 correction factors. The 2004 Late strength from HH-RG samples was best improved with the correction factor from ALL fibers combined. Fiber properties with less LSM differences showed less improvement with correction factor, such as the MH-RG micronaire values.

Following development of optimal correction factors, the sample data from 2004 was pooled, corrected, and spatially plotted in ArcView. A surface was interpolated from the individual data points using a spline, with 0.1 weight, 12 points and regularized. The surfaces from $\mathrm{MH}-\mathrm{PG}$, $\mathrm{MH}-\mathrm{RG}$ uncorrected and corrected fiber length are presented in Figure 2. The corrected surface shows improved similarity to the control MH-PG surface, though the specific distribution of length is not precise. Most notable are the high values at the northeast corner, and upper west edge of the field. The hand-harvested lengths showed even greater differences, even after correction (Figure 3). Differences in spatial structure are more apparent in the surface from handharvested samples. While the correction will improve the accuracy of spatial detail, development of correlations of fiber properties with underlying soil factors will be limited by research-induced errors in the sample handling. Substantial differences in the spatial structure still exist between the control (MH-PG) and the corrected spatial maps. 


\section{SUMMARY}

Some improvement in accuracy of fiber properties was attained using the correction factors developed here. However, some fiber properties showed no improvement with correction. For some parameters, no consistent correction factor was observed. Although improvement in the accuracy of spatial maps was evident, the underlying spatial structure was still significantly different between research and production methods of harvest and ginning. It may not be possibly to accurately translate from small-scale research studies to full-scale production results. This error in measurement will need to be recognized in studies exploring differences in spatial distribution of agronomic properties.

The research gin does no pre-processing of the cotton, but has only the saws to separate the lint and seed, after which the lint passes through rollers to the collection area. The production gin, in contrast, pre-processes the cotton by drying with heat, and removing trash and leaf material with stick machines and lint cleaners. The trend in decreased fiber length with the producer-scale gin most likely results from the extra processing of the fibers through the lint cleaners, as has been previously noted (Williford et al., 1984).

In this study, the bias towards better cotton lint observed previously with hand-harvested samples (Calhoun et al., 1996) was reduced by harvesting all bolls within a given length of row. While this improved the degree to which hand-harvested bolls mirrored machine-harvested lint, the time and labor required to harvest the number and distribution of hand-harvested samples for accurate development of spatial maps of fiber quality limits the use of this method in production settings.

In future work, we will test the methods developed here on production fields The spatial relationships of the fiber properties can then be explored, and correlated with underlying field conditions, such as soil nutrient and hydraulic characteristics, elevation, and environment.

\section{ACKNOWLEDGEMENT:}

The author wishes to thank Mr. Stanley Anthony for generous use of the ginning technology and Mrs. Debbie Boykin for assistance with the statistical analysis. The author would also like to recognize the contributions of an anonymous reviewer to suggested improvements in the manuscript.

\section{DISCLAIMER:}

Mention of a trade name is for informational purposes only and does not indicate an endorsement by the USDA in preference to others that may be available. 


\begin{abstract}
ABBREVIATIONS:
MH-PG: machine harvested, production ginned; $\mathrm{MH}-\mathrm{RG}$ : machine harvested, research ginned; HH-RG: hand harvested, research ginned.
\end{abstract}

\title{
5. REFERENCES
}

Braden, C., C.W. Smith, and P. Thaxton. 2004. Determining gin variability for HVI and AFIS data. p. 1113. In Proc. Beltwide Cotton Conf., San Antonio, TX. 5-9 Jan. 2004. Natl. Cotton Counc. Am., Memphis, TN.

Calhoun, D.S., T.P. Wallace, W.S. Anthony, and M.E. Barfield. 1996. Comparison of lint fraction and fiber quality data from hand- vs machine-harvested samples in cotton yield trials. $p$. 611-615. In Proc. Beltwide Cotton Conf., Nashville, TN. 9-12 Jan. 1996. Natl. Cotton Counc. Am., Memphis, TN.

Davidonis, G.H., A.S. Johnson, and R.M. Johnson. 2004. Quantification of within-plant and within-field yield an fiber variability. Crop Management. doi:10.1094/CM-2004-0121-01-RS [Online]. Available at: http://www.plantmanagementnetwork.org/pub/cm/research/2004/fiber/ (verified 6 Mar. 2006).

Dunn, T.A., S.K. Misra, G.L. Barker, and R.V. Baker. 2002. Predicting lint cleaner efficiency and fiber quality characteristics in cotton ginning. Applied Engineering in Agriculture. Vol 18(2):141-146.

Elms, M.K., and C.J. Green. 1997. Spatial variability of yield in irrigated cotton. p. 598-601. In Proc. Beltwide Cotton Conf., New Orleans, LA. 7-10 Jan. 1997. Natl. Cotton Counc. Am., Memphis, TN.

Elms, M.K., and C.J. Green. 1998. Cotton yield variability and correlations between yield, previous yield, and soil properties. p. 630-636. In Proc. Beltwide Cotton Conf., San Diego, CA. 5-9 Jan. 1998. Natl. Cotton Counc. Am., Memphis, TN.

Elms, M.K., C.J. Green, and P.N. Johnson. 2001. Variability of cotton yield and quality. Communications in Soil Science and Plant Analysis. 32 (3\&4):351-368.

Gannaway, J., E. Hequet, R. Boman, M. Kelley, and R. Nichols. 2004. Grab samples versus commercially ginned bales: A Texas High Plains comparison. p. 1098 In Proc. Beltwide Cotton Conf., San Antonio, TX. 5-9 Jan. 2004. Natl. Cotton Counc. Am., Memphis, TN.

Guo, W., S. Maas, E. Hequet, R. Lascano, and J. Brightbill. 2004. Variability of cotton fiber quality in West Texas. p. 2318 - 2325. In Proc. Beltwide Cotton Conf., San Antonio, TX. 5-9 Jan. 2004. Natl. Cotton Counc. Am., Memphis, TN. 
Johnson, R.M., R.G. Downer, J.M. Bradow, P.J. Bauer, and E.J. Sadler. 2002. Variability in cotton fiber yield, fiber quality, and soil properties in a Southeaster coastal plain. Agronomy Journal. 94:1305-1316

Ping, J.L., C.J. Green, K.F. Bronson, R.E. Zartman, and A. Dobermann. 2004. Idenfication of relationships between cotton yield, quality, and soil properties. Agronomy Journal. 96:15881597.

Sassenrath, G.F., J.R. Williford, and H.C. Pringle. 2004. Measuring the spatial variability of cotton fiber properties. p. 2312-2317. In Proc. Beltwide Cotton Conf., San Antonio, TX. 5-9 Jan. 2004. Natl. Cotton Counc. Am., Memphis, TN.

Sassenrath, G.F., E.R. Adams, and J.R. Williford. 2005. Rapid sampling system for determination of cotton fiber quality spatial variability. Applied Engineering in Agriculture. 21(1):9-14

Wilkerson, J.B., F.H. Moody, W.E. Hart, and P.A. Funk. 2001. Design and evaluation of a cotton flow rate sensor. Trans ASAE. 44(6):1415-1420.

Williford, J.R., W.R. Meredith, Jr., and A.C. Griffin, Jr. 1984. Effect of variety, harvest method, and lint cleaners on cotton quality and value in 1983. p. 114-115. Proc. Beltwide Cotton Prod. Res. Conf., Atlanta, GA. 8-12 Jan. 1984. Natl. Cotton Counc. Am., Memphis, TN.

Williford, J.R., W.R. Meredith, and W.S. Anthony. 1987. Factors influencing yield and quality of Delta cotton. Transactions of the American Society of Agricultural Engineers. 30(2):311-316.

Williford, J.R. 1992. Influence of harvest factors on cotton yield and quality. Transactions of the American Society of Agricultural Engineers. Vol. 35(4):1103-1107. 
Table 2. Differences in Least Square Mean for micronaire and strength.

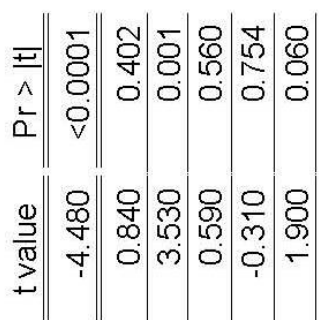

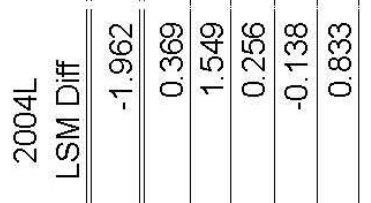

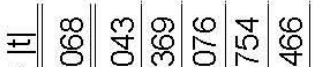

\begin{tabular}{llllllll}
$\hat{2}$ & 0 & 0 & 0 & 0 & 0 & 0 \\
\hline
\end{tabular}

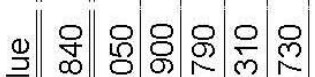

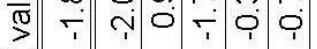

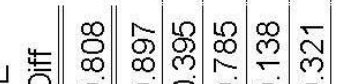

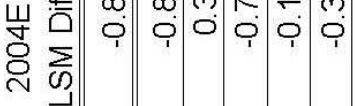

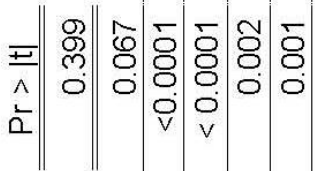

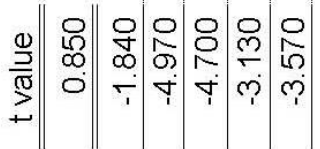

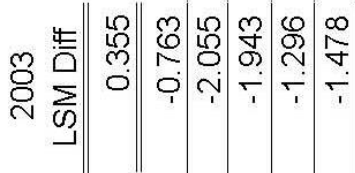

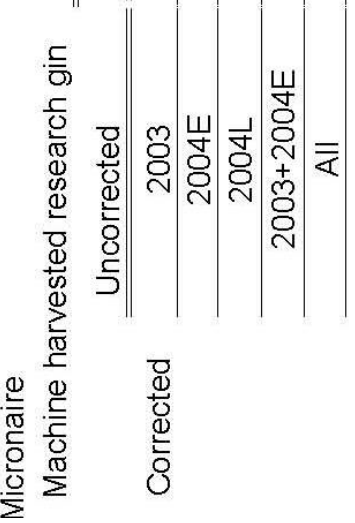

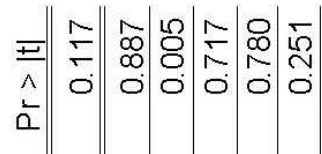

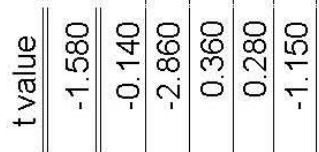

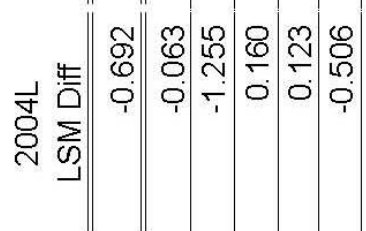

프 윳융융 용용

玄

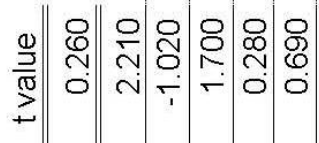

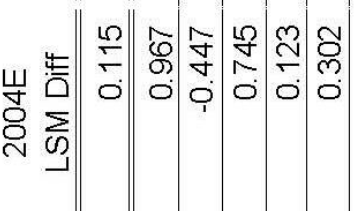

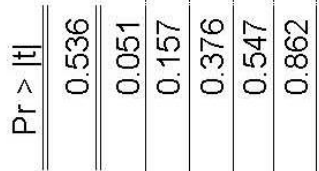

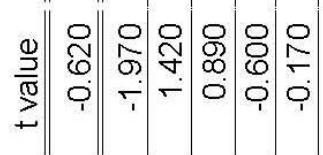

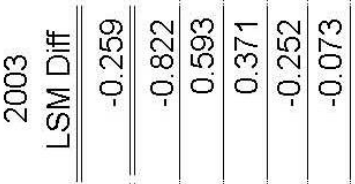

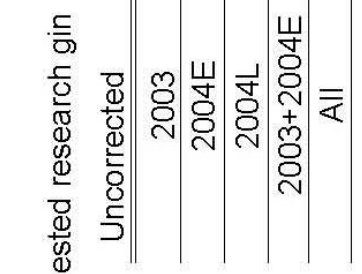

旁

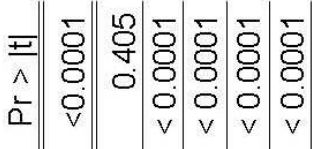

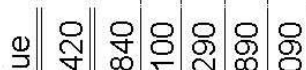

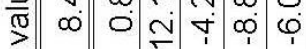

守

프 ㅇํㅇ

A

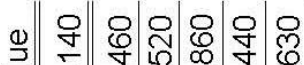

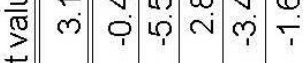

o

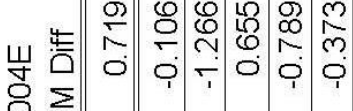

응

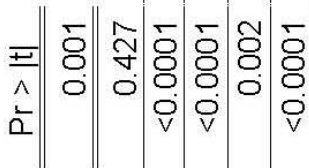

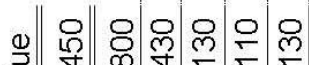

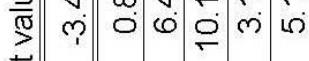

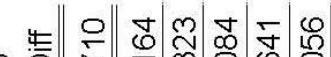

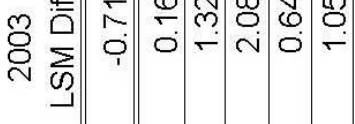

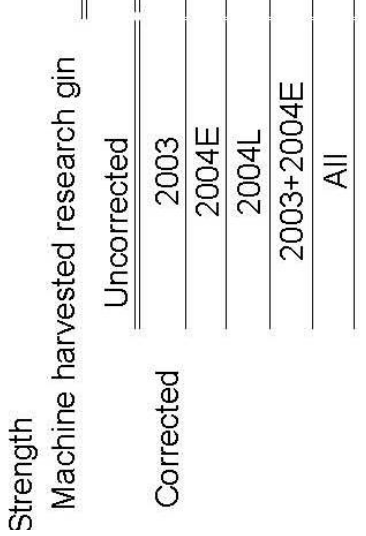

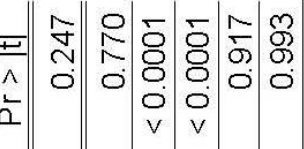

네 오올음옹으은

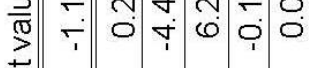

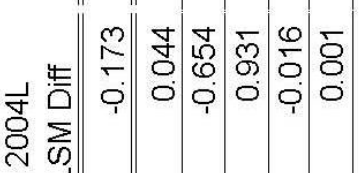

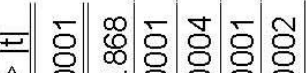

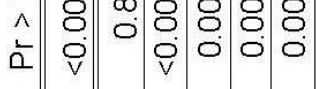

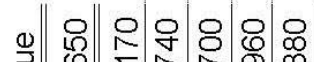

د

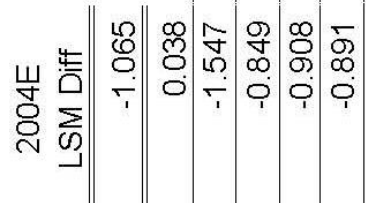

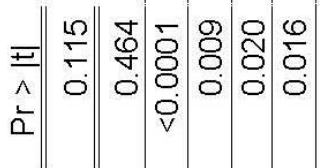

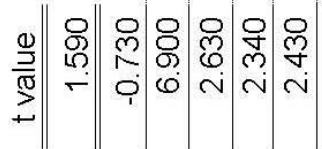

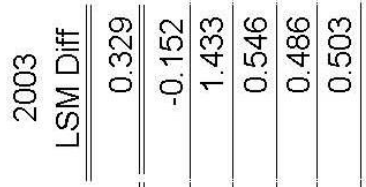

(1) 
Table 3. Differences in Least Square Mean for Length and Uniformity.

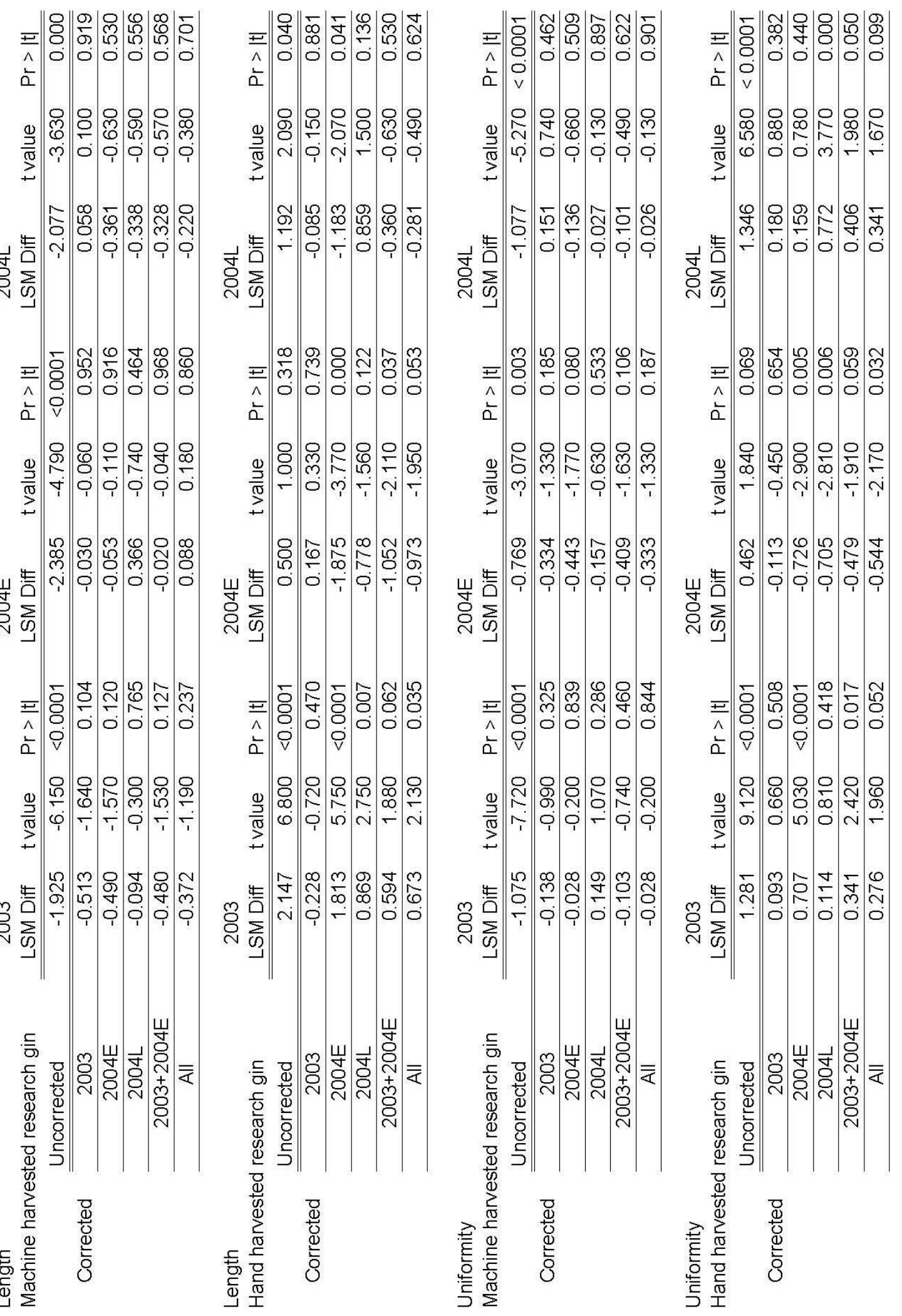




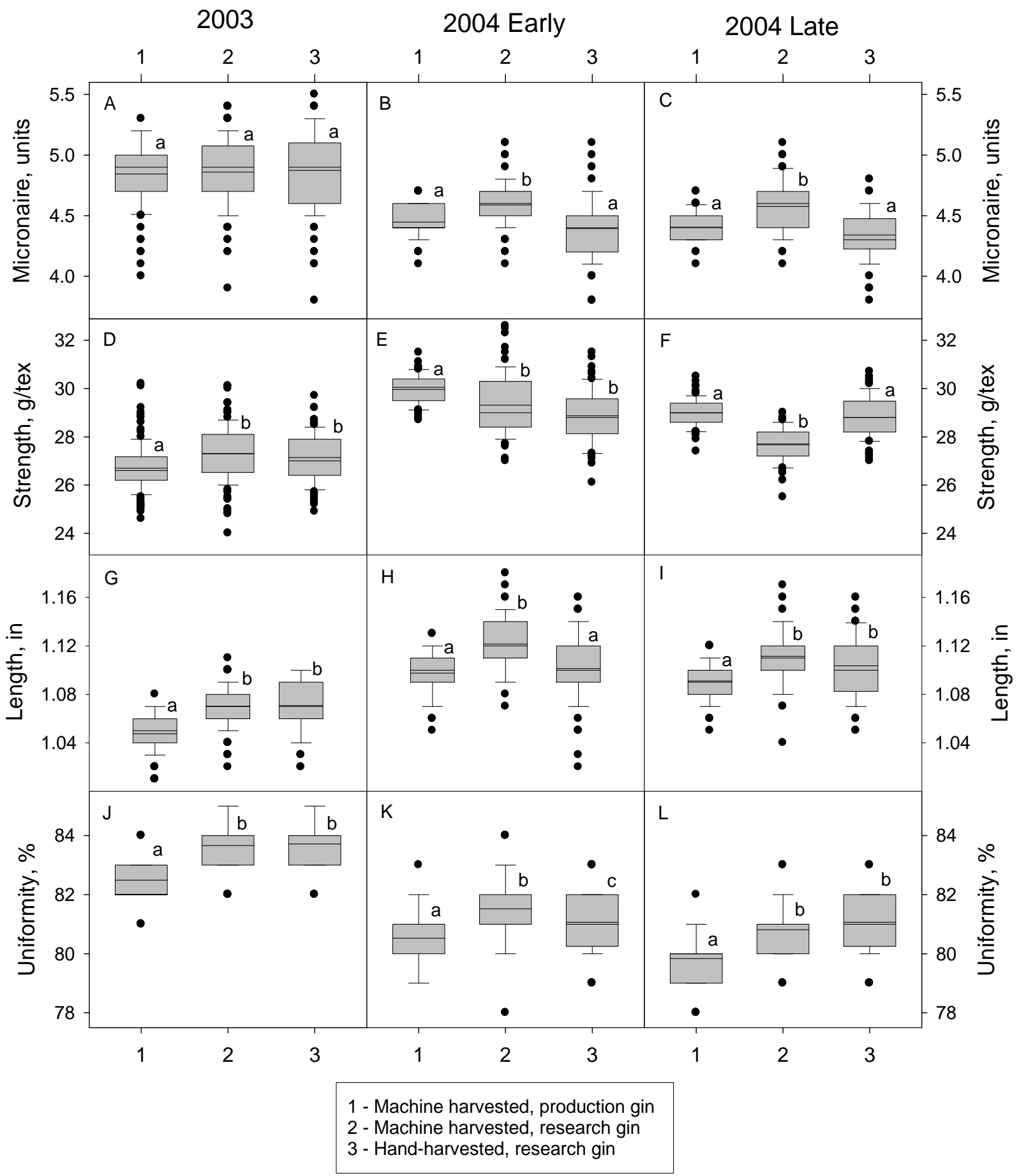

Figure 1. Mean and distribution of micronaire, strength, length and uniformity for 2003, and Early and Late 2004 harvests. Distributions which are statistically significant at the $95 \%$ confidence level within a given year are noted as different letters above the box-plots. 


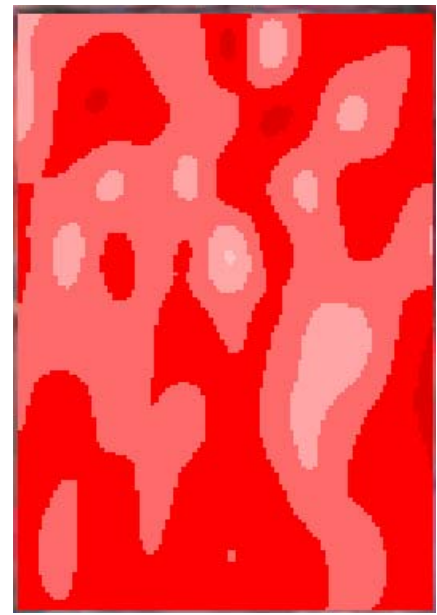

A. MH-PG, Control Length, 2004 Early

F iber Length, $1 / 100$ in
\begin{tabular}{|l}
\hline \\
$100-102.5$ \\
$102.5-105$ \\
$105-107.5$ \\
$107.5-110$ \\
$110-112.5$ \\
$112.5-115$ \\
$115-120$ \\
$120-125$ \\
$125-130$ \\
$130-135$
\end{tabular}

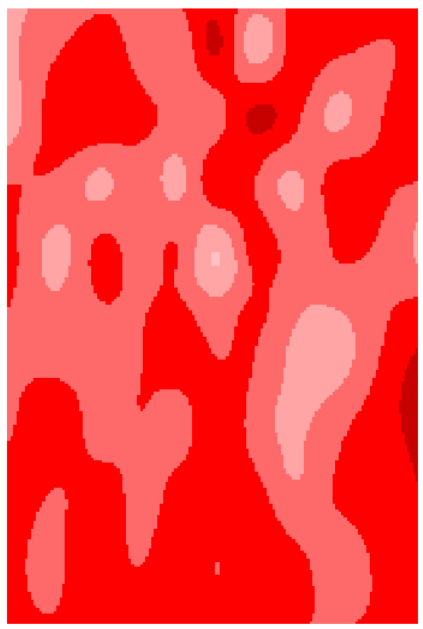

A. MH-PG, Control Length, 2004 Early

Fiber Length, $1 / 100$ in
\begin{tabular}{|l}
\hline$\square$ \\
$100 \cdot 102.5$ \\
$102.5 \cdot 105$ \\
$105 \cdot 107.5$ \\
$107.5 \cdot 110$ \\
$110 \cdot 112.5$ \\
$112.5 \cdot 115$ \\
$115 \cdot 120$ \\
$120 \cdot 125$ \\
$125 \cdot 130$ \\
$130 \cdot 135$
\end{tabular}

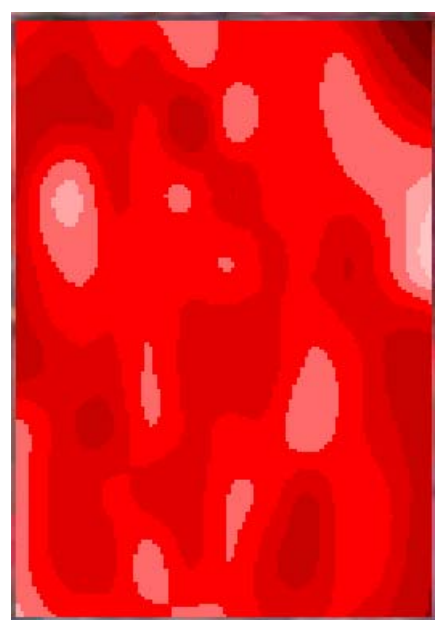

B. MH-RG, uncorrected Length, 2004 Early

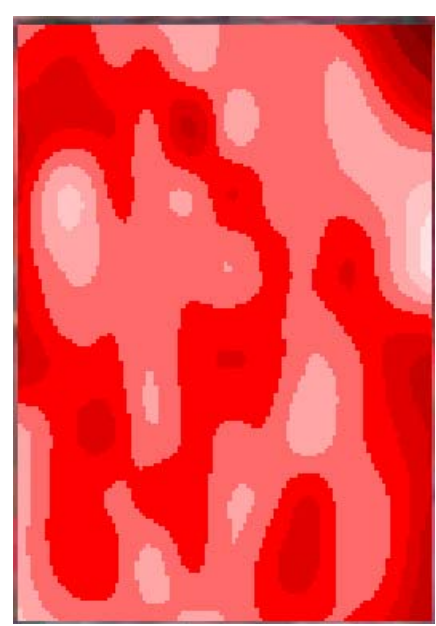

C. MH-RG, corrected Length, 2004 Early

Figure 2. Surface of all data points from (A) machine harvested, production gin, (B) uncorrected machine harvested research gin, and (C) machine harvested research gin, corrected with factor from 2003+2004E for fiber length.

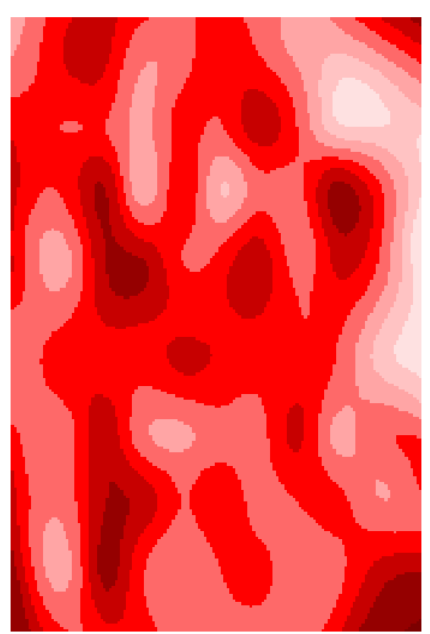

B. HH-RG, uncorrected Length, 2004 Early

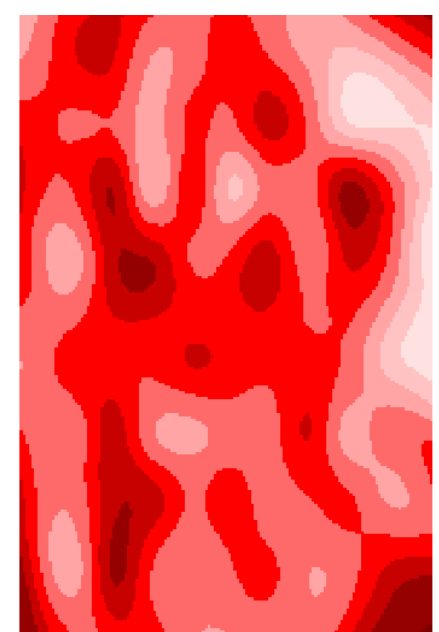

C. HH-RG, corrected Length, 2004 Early

Figure 3. Surface of all data points from (A) machine harvested, production gin, (B) uncorrected hand harvested research gin, and (C) hand harvested research gin, corrected with factor from 2003 for fiber length. 